Abstract P273 Table 1 Baseline characteristics of IPF patients aged $>80$ and $<80$ years

\begin{tabular}{llll}
\hline & IPF aged $>80$ & IPF aged $<80$ & p value \\
\hline Mean age & $81,60 \pm 2,671$ & $67,89 \pm 7,538$ & \\
Smokers (current-former) & $31 / 51(60 \%)$ & $209 / 317(66 \%)$ & NS \\
Pack-year history & $13,38 \pm 19,23$ & $16,43 \pm 20,45$ & NS \\
FEV 1 & $82,24 \pm 16,87$ & $73,14 \pm 18,36$ & $\mathrm{P}=0.002$ \\
FVC & $77,45 \pm 18,61$ & $70,50 \pm 20,46$ & $\mathrm{P}=0,024$ \\
DLco & $36,26 \pm 14,92$ & $36,30 \pm 14,17$ & NS \\
Kco & $67,50 \pm 22,65$ & $68,69 \pm 19,64$ & NS \\
\hline
\end{tabular}

\section{P274 COGNITIVE FUNCTION IN IDIOPATHIC PULMONARY FIBROSIS}

${ }^{1} \mathrm{C}$ Sharp, ${ }^{2} \mathrm{HI}$ Adamali, ${ }^{1} \mathrm{AB}$ Millar, ${ }^{1} \mathrm{JW}$ Dodd. ${ }^{1}$ Academic Respiratory Group, University of Bristol, Bristol, UK; ${ }^{2}$ Bristol Interstitial Lung Disease (BILD) Service, North Bristol NHS Trust, Bristol, UK

\subsection{6/thoraxjnl-2016-209333.417}

Introduction Patients with Chronic Obstructive Pulmonary Disease (COPD) are known to have cognitive dysfunction and share many co-morbidities with those with Idiopathic Pulmonary Fibrosis (IPF). This led us to hypothesise that patients with IPF may also have cognitive dysfunction. To investigate this, we conducted a prospective, observational study examining cognitive function in IPF patients with normal oxygen saturations, comparing them to COPD and smoking controls.

Methods Patients with IPF and oxygen saturations $>88 \%$ in room air were recruited from outpatient clinics. Exclusion criteria were dementia, neurological disease and illiteracy. Data from the NOVASC study were used for the COPD and control arms.

Pulmonary physiology results and demographic data, including educational and smoking status were collected. Patients completed the Montreal Cognitive Assessment (MoCA) and Hospital Anxiety and Depression Scale (HADS).

Group differences were assessed using unpaired t-test, analysis of variance and $\chi 2$ test. Multivariable linear regression models were constructed to establish which variables contributed to observed variability in MoCA results.
Results 30 patients with IPF were recruited and were compared to 31 patients with COPD and 26 smoking controls. Results are shown in Table 1. MoCA scores were lower in both IPF and COPD groups and a greater proportion of IPF patients had scores in the "mild cognitive dysfunction" range of 18-25 (46.7\%, compared to COPD 32.3\%, control 11.5\%, $\mathrm{p}=0.018$ ).

We also compared the IPF cohort to normative data in a population aged 70-79. The mean MoCA in this population was 27.5 $(\mathrm{SD}=5.56, \mathrm{n}=53)$. The IPF patients had a significantly lower MoCA score $(\mathrm{p}=0.035)$.

A multivariable linear regression model including diagnosis, age, education and FVC predicted $18.8 \%$ of the variance in $\operatorname{MoCA}(\mathrm{F}(4,79)=4.57, \mathrm{p}=0.002)$. Age was the only significant variable.

Conclusions $46.7 \%$ of non-hypoxaemic patients with ILD demonstrate at least mild cognitive dysfunction, some of this can be explained by the effect of age, but compared to published age adjusted normative data, there remains a significant reduction in cognitive function in IPF. This cognitive dysfunction has implications for decision making around treatments in IPF which may have significant side-effects.

\section{P275 PATIENT UNDERSTANDING, EXPECTATIONS AND EXPERIENCES OF AN INTERSTITIAL LUNG DISEASE SPECIALIST CENTRE}

${ }^{1} \mathrm{M}$ Lee, ${ }^{2} \mathrm{M}$ Bennett, ${ }^{2} \mathrm{C}$ Leonard, ${ }^{2} \mathrm{~N}$ Chadhuri. ${ }^{1}$ University of Manchester, Manchester, UK; ${ }^{2}$ University Hospital of South Manchester, Manchester, UK

\subsection{6/thoraxjnl-2016-209333.418}

Introduction Interstitial lung disease is the collective term used for a group of scarring lung conditions associated with debilitating symptoms, reduced life expectancy and a poor quality of life. NHS England commissioned ILD specialist centres to help co-ordinate patient care, arrive at accurate diagnoses faster and monitor the use of newly licensed anti-fibrotic medication. This qualitative study evaluates if specialist services significantly improves patient understanding and experiences of their disease. Method A two-part questionnaire was handed to new patients at an ILD specialist centre, part one assessed patient perspective before their appointment and part two after. Before and after

Abstract P274 Table 1 Demographic and physiology results

\begin{tabular}{|c|c|c|c|c|c|}
\hline Variable & IPF $(\mathrm{n}=30)$ & $\operatorname{COPD}(\mathrm{n}=31)$ & $\begin{array}{l}\mathrm{P} \text { (t-test } / \chi^{2} \text { between } \\
\text { IPF/COPD) }\end{array}$ & Control $(n=26)$ & $\begin{array}{l}\mathrm{P} \text { (t-test } / \chi^{2} \text { between } \\
\text { IPF/control) }\end{array}$ \\
\hline Gender ( $\%$ male) & $67 \%$ & $52 \%$ & 0.232 & $54 \%$ & 0.327 \\
\hline Age & $75.6(5.8)$ & $66.6(7.1)$ & $<0.001$ & $62.9(9.6)$ & $<0.001$ \\
\hline BMI & $25.4(3.6)$ & $28.4(5.2)$ & 0.011 & $27.4(5.3)$ & 0.111 \\
\hline Pack years smoking & $15.1(18.9)$ & $41.6(22.8)$ & $<0.001$ & $29.2(16.1)$ & 0.005 \\
\hline$<12$ years full-time education & $33.3 \%$ & $77.4 \%$ & 0.001 & $80.8 \%$ & $<0.001$ \\
\hline MoCA & $25.2(2.6)$ & $25.5(2.8)$ & 0.649 & $27.2(2.2)$ & 0.005 \\
\hline HADS & $7.6(5.0)$ & $9.5(5.4)$ & 0.150 & $6.6(4.8)$ & 0.457 \\
\hline FEV1 (\%) & $89.6(18.4)$ & $57.1(18.7)$ & $<0.001$ & $99.6(19.2)$ & 0.052 \\
\hline FVC (\%) & $88.1(24.4)$ & $86.7(20.1)$ & 0.805 & $110.3(19.0)$ & 0.001 \\
\hline Ratio & $0.8(0.07)$ & $0.54(0.13)$ & $<0.001$ & $0.69(0.28)$ & 0.036 \\
\hline DLCO (\%) & $51.7(15.1)$ & $\mathrm{N} / \mathrm{A}$ & & N/A & \\
\hline So2 (\%) & $94.7(1.9)$ & $\mathrm{N} / \mathrm{A}$ & & $\mathrm{N} / \mathrm{A}$ & \\
\hline
\end{tabular}

IPF - Idiopathic Pulmonary Fibrosis, COPD - Chronic Obstructive Pulmonary Disease, BMI - Body Mass Index, MoCA - Montreal Cognitive Assessment, HADS - Hospital Anxiety and Depression Scale, $\mathrm{FEV}_{1}$ - forced expiratory volume in 1 second, FVC - forced vital capacity, DLCO - diffusing capacity for carbon monoxide, So ${ }_{2}$ - Oxygen saturations 
results were compared against one another using a paired t-test. Total of 46 sets of data collected.

Results Patients felt they were given more information about their diagnosis (mean $5.15->9.08$, p value $<0.0001$ ), prognosis (mean $4.76->9.04$, p value $<0.0001$ ) and treatment options (mean $4.63->9.28$, p value $<0.0001$ ). Patients felt they had more control over their disease (mean $3.67->6.66$, p value $<0.001$ ) and more confidence they were being managed correctly (mean $4.39->8.52$, p value $<0.001$ ). Patients felt more satisfied with their care after being seen at an ILD specialist clinic (mean $6.04->9.44$, p value $<0.0001$ ). More patients strongly agreed information given met their expectations (7/45 $>37 / 46$ ) and was delivered in a way that was clear and easy to understand (11/45 - >36/45). 87\% (40/46) of patients strongly agreed there is more benefit in being seen at a specialist centre. Conclusion Evidence supports the utilisation of specialist centres to manage patients with ILD. Results show there is a significant improvement in patient understanding, experiences and satisfaction.

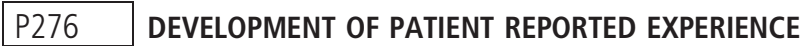 MEASURE (PREM) FOR IDIOPATHIC PULMONARY FIBROSIS (IPF)}

${ }^{1}$ AM Russell, ${ }^{2} S$ Sonecha, ${ }^{3} \mathrm{~A}$ Datta, ${ }^{4} \mathrm{R}$ Hewitt, ${ }^{2}$ I Howell, ${ }^{2} \mathrm{~A}$ Elliott, ${ }^{4} \mathrm{M}$ Wickremasinghe. ${ }^{1}$ National Heart and Lung Institute, London, UK; ${ }^{2}$ Roche Products Limited, Welwyn Garden City, UK; ${ }^{3}$ Northwick Park Hospital, London, UK; ${ }^{4}$ Imperial College NHS Healthcare Trust, London, UK

\subsection{6/thoraxjnl-2016-209333.419}

Background Research into patient experiences of living with IPF has increased. A key challenge is how to use this data intelligently to enable commissioners and providers to improve the quality of services delivered to this group of patients. This project aims to develop an IPF-PREM informed by patients' perceptions of their healthcare experiences. The IPF-PREM is underpinned by the NHS Patient Experience Framework (NPEF); ${ }^{1}$ National Institute for Health and Care Excellence (NICE) Quality Standards (QS15 and 79) and aligned to national initiatives integrating Patient Reported Outcome Measures (PROMs) and PREMs into NHS care.
Methods A scoping exercise was undertaken with patients diagnosed with IPF on their journey through the healthcare system covering eight areas corresponding to the NPEF. ${ }^{1}$ Twenty patients representing all stages of the disease trajectory participated in one of three focus groups. Transcripts underwent content and thematic analysis. Patient preferences were also sought on questionnaire design.

Results A number of key themes emerged. See Table 1. Of particular importance were issues concerning access: to specialist centres, medication and primary care services; consistency of care to prevent confusion; coordination of care especially for patients with multi-morbidities and getting the right information at the right time in the right way. Information enabling practical selfmanagement was highly valued. Overarching was the need for continuity of care close to home. Participants valued having a nurse to co-ordinate care and to talk to at all stages of the care pathway. The response categories patients were keen to avoid were visual images such as smiley faces.

Conclusions The IPF-PREM will provide a valuable quality indicator for IPF service delivery at all stages of the disease trajectory complementing IPF PROMs. Implementation of the PREM will enable commissioners and providers to improve the quality of the services and the patient experience of care delivered across the wider inter-disciplinary team.

\section{REFERENCE}

1 DH 2011 NHS Patient Experience Framework.

\section{P277 MEASURING SEDENTARY BEHAVIOURS IN PATIENTS WITH IDIOPATHIC PULMONARY FIBROSIS USING WRIST- WORN ACCELEROMETERS}

${ }^{1} \mathrm{CP}$ Atkins, ${ }^{2} \mathrm{M}$ Baxter, ${ }^{1} \mathrm{AP}$ Jones, ${ }^{1} \mathrm{AM}$ Wilson. ${ }^{1}$ Norwich Medical School, University of East Anglia, Norwich, UK, ${ }^{2}$ Norfolk and Norwich University Hospital, Norwich, UK

\subsection{6/thoraxjnl-2016-209333.420}

Introduction Idiopathic pulmonary fibrosis (IPF) patients suffer increasing functional limitation as the disease progresses. Increasing sedentary behaviour (SB) time has been associated with poorer health-related quality of life. Determining thresholds for activity vigour in patients with respiratory disease is difficult due to variability in cardiorespiratory limitations between individuals.

\begin{tabular}{|c|c|}
\hline NPEF domain & Focus group themes \\
\hline Respect for patient-centred values & $\begin{array}{l}\text { Recalibrating quality of life and wanting feedback on PROMs data; impact of breathlessness on independence; the need to talk and the need not to } \\
\text { talk to be respected }\end{array}$ \\
\hline Coordination and integration of care & Challenges of managing other health issues and lack of social/fiscal support - administrative processes often a barrier \\
\hline $\begin{array}{l}\text { Information, communication and } \\
\text { education }\end{array}$ & $\begin{array}{l}\text { The need to talk to others affected with IPF; more information at the beginning; to understand choices in healthcare; information customised to } \\
\text { specific needs }\end{array}$ \\
\hline Physical comfort & Impact on activities of daily life and how to physically manage these - support with transitions to oxygen therapy; need for effective symptom relief \\
\hline Emotional support & $\begin{array}{l}\text { Better access to psychological/counselling services for self and caregivers. Value having telephone support; healthcare professionals responding } \\
\text { promptly to requests for advice. Wanting and not wanting to know prognosis }\end{array}$ \\
\hline Involvement of family and friends & $\begin{array}{l}\text { Family may have different information needs - respecting patient's wishes - support for wives'; husband's; partners often lacking - guilt associated } \\
\text { with burden of caring }\end{array}$ \\
\hline Transition and continuity & $\begin{array}{l}\text { Do not want to be abandoned at end of life - feel better supported by clinicians known at diagnosis. Value copies of correspondence. Value having } \\
\text { a key contact - particularly specialist nurse }\end{array}$ \\
\hline Access to care & $\begin{array}{l}\text { Having a progressive condition makes waiting to be seen by a specialist centre or for transplant assessment stressful. Travel presents challenges: } \\
\text { dichotomy of wanting care close to home but with specialist input; too many health care appointments }\end{array}$ \\
\hline
\end{tabular}

